ORIGINAL ARTICLE

\title{
Prevention of work related eye injuries: long term assessment of the effectiveness of a multicomponent intervention among metal workers
}

\author{
G Mancini, A Baldasseroni, G Laffi, S Curti, S Mattioli, F S Violante
}

Occup Environ Med 2005;62:830-835. doi: 10.1136/oem.2004.019570

See end of article for authors' affiliations

Correspondence to: Dr S Mattioli, Laboratorio di Epidemiologia, Unità Operativa di Medicina del Lavoro, Policlinico

Sant'Orsola Malpighi, via Pelagio Palagi n.9, 1-40138 Bologna, Italy; smattioli@aosp.bo.it

Accepted 18 May 2005

\begin{abstract}
Background: Systematic assessments of the effectiveness of interventions to prevent work related eye injuries are needed.

Aim: To investigate the long term effectiveness of a multicomponent prevention campaign.

Methods: The campaign (conducted in collaboration with the local Employers' Association and Trade Unions) targeted all 237 metal-ware factories in the district of Imola, Italy. Based on preliminary inspections, the main intervention included distribution to all factories of specific educational brochures and broadcasting/publication of television/radio programmes and local newspaper articles containing expert advice on the subject. This was followed by a four year "post-intervention reinforcement" period of unannounced official inspections. Main outcome measures analysed were eye injury rates (versus non-eye injury rates) among metal workers during "pre-intervention" (1988-90), "peri-intervention" (1991-92), "post-intervention reinforcement" (1993-96), "late post-intervention" (1997-2000), and "very late postintervention" (2001-03) periods with respect to two comparison sectors (construction and wood/ ceramics).

Results: A Poisson regression in which the eye injury rates were modelled for each sector, period, and interaction, adjusting for non-eye injury rates, was chosen. The periods did not by themselves determine an overall reduction in eye injuries. The period/sector interaction terms were related to significant reductions for the metal sector when crossed with the "post-intervention reinforcement" (IRR $=0.77,95 \%$ $\mathrm{Cl} 0.61$ to 0.97 ; \% decline $=23.4$ ), the "late post-intervention" (IRR=0.63, $95 \% \mathrm{Cl} 0.50$ to $0.79 ; \%$ decline $=37.4)$, and the "very late post-intervention" (IRR= $0.58,95 \% \mathrm{Cl} 0.43$ to $0.77 ; \%$ decline $=42.4)$ periods, suggesting a sustained reduction in eye injury risk following the main intervention.

Conclusion: Results suggest that a carefully coordinated, extensive, multicomponent intervention can lead to lasting reductions in the burden of eye injuries.
\end{abstract}

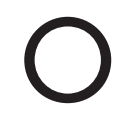
ccupational eye injuries constitute a major social and economic problem despite workplace safety laws stipulating mandatory utilisation of individual protective devices. ${ }^{1-3}$ In 2000, The Bureau of Labour Statistics ${ }^{4}$ reported 53800 occupational eye injuries responsible for lost workdays, per year in private industry, in the United States, while in 1999 the Italian National Institute of Insurance for Occupational Accidents (INAIL) compensated over 27000 eye injuries causing more than three lost workdays, 8300 of which were in metal workers. ${ }^{5}$ Along with high social costs, eye injuries can cause psychological distress since they involve a key sense organ. Although most cases carry a favourable prognosis, some injuries can cause permanent lesions or loss of sight. In a recent systematic review, Lipscomb $^{6}$ identified only seven reported studies of the effectiveness of interventions to prevent occupational eye injuries with an appropriate outcome measure. In the single study that included a comparison group, Smith and coworkers ${ }^{7}$ reported a more consistent decrease in the incidence of eye injuries among metal workers after the intervention, but no statistical analysis was performed. More rigorous, systematic assessment of the effectiveness of such interventions is needed. ${ }^{6}$

In the early 1990s, the public Occupational Health Service of Imola (in northern Italy), implemented a multicomponent local educational campaign specifically designed to reduce the burden of eye injuries among metal workers. In this paper, we assess the medium and long term effectiveness of this preventive intervention.

\section{METHODS}

\section{Background}

Since 1982, the public Occupational Health Service (a branch of the Italian national health service) of Imola has run a local surveillance system for occupational injuries based on an agreement with the single local hospital, whereby records ("first certificates") are filed for all injuries-regardless of the number of days off work-occurring in the town and the seven surrounding municipalities (falling within the Local Health Authority of Imola). This system appears to be particularly comprehensive because Imola's single hospital has the most easily reached emergency room in the zone. The certificate bears important information, including personal details and clinical characteristics of the worker; identification of the factory and the industrial sector; kind of injury; date and time of occurrence; how the injury took place; and number of days off work. Furthermore the data collection is more complete than that of the INAIL database, which records only cases involving at least four lost working days (making it difficult to carry out a study on eye injuries, which include many cases with no more than three lost working days ${ }^{8}$ ).

The Occupational Health Service of Imola noticed that among the occupational injuries recorded in $1988(\mathrm{n}=3238)$, almost one third $(n=1043)$ were eye injuries. Moreover, $72 \%$ of the eye injuries were in metal workers, most often in factories employing no more than 10 workers. This observation prompted the Occupational Health Service to initiate an extensive multicomponent prevention programme specifically aimed at reducing occupational eye injuries in metal workers. 


\section{Description of the intervention}

Preliminary assessment and intervention planning In a preliminary phase (May-June 1990), the major reasons for the high incidence of eye injuries in the setting were investigated so as to aid promotion of tailored preventive measures. A convenience sample of 12 factories (from among the 237 that had reported eye injuries in 1988) were inspected, each employing 3-20 metal workers. These unannounced inspections were conducted by a team comprising a technician and two nurses, who recorded detailed observations regarding use of individual protective devicesincluding methods of choice, availability, maintenance, quality, and usage-and about protective systems mounted on or incorporated into machinery or other equipment. All the workers $(\mathrm{n}=90)$ of the 12 factories were also individually interviewed. It was found that only about $75 \%$ of the machinery provided protection from flying splinters/sparks. While all the employers provided individual protective devices, in about $50 \%$ of cases the devices were often not adopted (being non-personal, of low quality/visibility, nonspecific, not easily size adjustable, etc). These situational observations were used to draw up a tailored educational brochure providing detailed guidance on individual protective measures to be adopted in different metal-ware manufacturing tasks with different hazards/exposures. The brochure contained: (1) an introduction to the local situation, highlighting the frequency of eye injuries and the severity of some of the cases (this premise was designed to attract interest and motivate workers to adopt preventive actions); (2) list of atrisk situations for eye injuries and of common inappropriate behaviour; and (3) explanation of effective preventive actions, including appropriate selection/use of personal devices (in terms of adequate resistance, correct personal fit, comfort, and operational convenience). Focus group meetings were held with representatives of the local Employers' Association and Trade Unions to decide on organisational considerations for the main educational intervention, and to gain the collaboration of the individual companies.

\section{Main intervention}

Between December 1991 and June 1992, the main educational campaign targeted employers and employees of all the relevant metal-ware factories in the zone. During this phase, the tailored educational brochure about eye injuries in metal workers and technical/legal preventive measures was distributed to each metal worker. In addition, the brochure was distributed to vocational secondary schools, hospital emergency departments and waiting rooms, trade union offices, and town halls. Evening local television and radio interviews with an ophthalmologist and an occupational physician were broadcast, providing metal workers with specific expert advice on the importance of the use of different varieties of protective equipment in different situations for the prevention of eye injuries. Furthermore, educational articles specifically focused on eye injury prevention strategies for metal workers appeared in local newspapers and a free magazine with house-to-house distribution.

\section{Post-intervention reinforcement phase}

In 1993-96, unannounced official inspections were performed of 55 metal-ware factories $(n=33$ in 1993-94; $\mathrm{n}=22$ in 1995-96) using the same modalities as the preliminary inspections (see above). This was done to reinforce the message of the campaign (both directly in the inspected factories, and indirectly in neighbouring factories) and to monitor secondary outcomes. It should be noted that these official workplace inspections (conducted by public Occupational Health Service physicians and technicians)
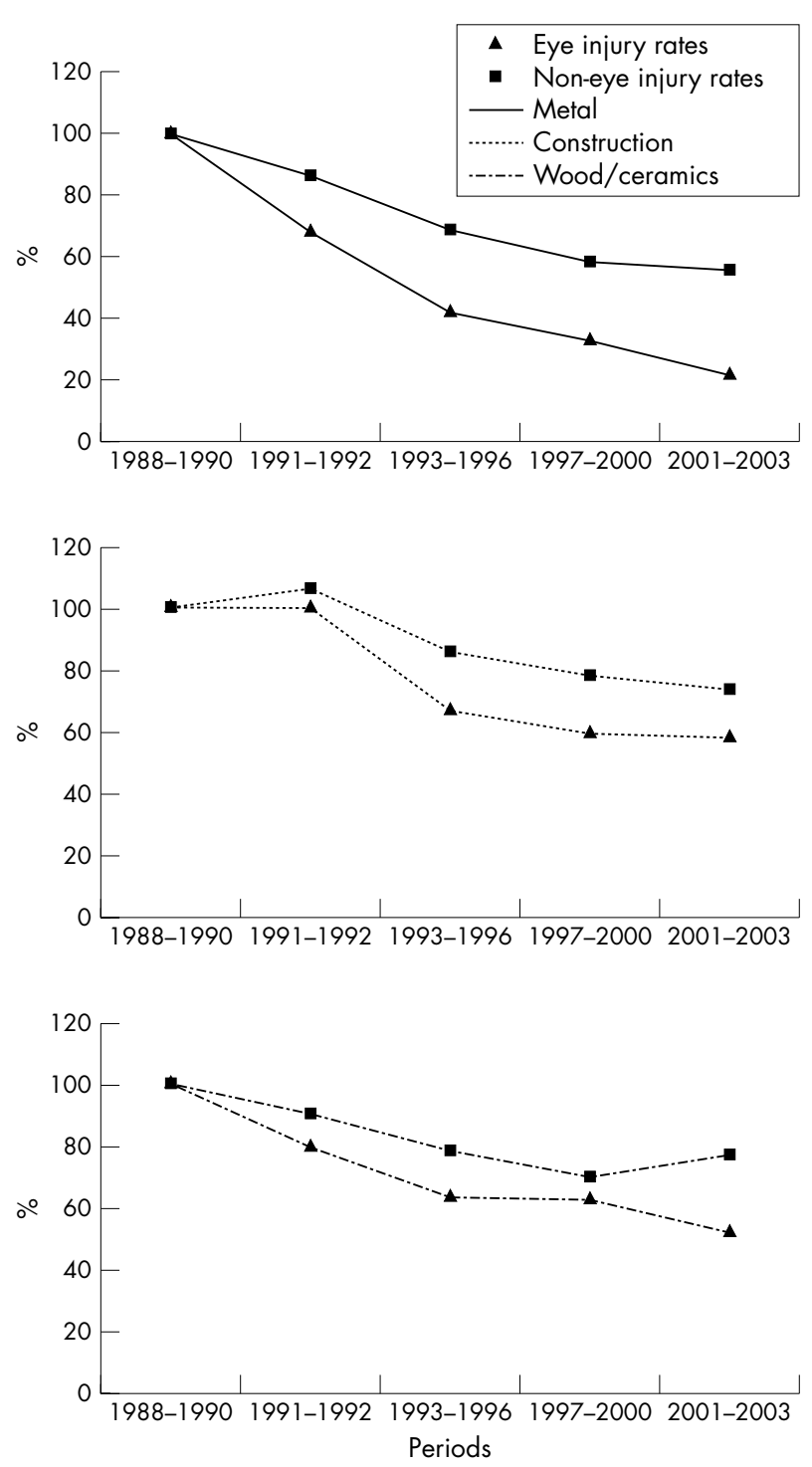

Figure 1 Indexed trends (with respect to the pre-intervention period, 1988-90) in rates of eye injuries and non-eye injuries in the sector under investigation (metal) and the comparison sectors (construction, wood/ ceramics) in the different study periods (peri-intervention, 1991-92; post-intervention reinforcement, 1993-96; late post-intervention, 19972000; very late post-intervention, 2001-03).

have legal powers under Italian legislation, ${ }^{9}$ and therefore carry a considerable "deterrent" value. It was found that all the employers and about $90 \%$ of the employees had been "exposed" to the brochure; $98 \%$ of employees had proper eye protection devices (personal ones in $64 \%$ of cases).

\section{Assessment of effectiveness}

Assessment of effectiveness was based on analysis of the comprehensive records compiled by the Imola Hospital Emergency Department. Since it was not feasible to collect data regarding numbers of blue-collar workers employed in specific sectors directly from each of the individual firms, numbers of blue-collar workers (in each sector) were estimated based on extrapolations around five yearly industrial census data for the eight municipalities corresponding to the Local Health Authority of Imola, as collected by ISTAT (the Italian National Institute of Statistics) in 1991, 1996, and 2001. ${ }^{10}$ (In particular, 1991 census data were used for each of the years 1988 to 1993 ; 1996 data for 1994 to 1998 ; 
2001 data for 1999 to 2003.) We used the resulting figures to compare rates (calculated for the duration of each period) of occupational eye injuries recorded among metal workers and workers in two other locally predominant sectors not "exposed" to our intervention (comparison sectors)namely, (1) construction, and (2) wood/ceramics (grouped together because of the limited number of eye injuries). In performing this comparison, we also took into account trends recorded in non-eye injuries (that is, injuries occurring in any other part of the body) during the overall study period.

Five different periods were predefined for analysis: "preintervention" (1988-90); "peri- intervention" (1991-92, a period selected to take in any effects of the pre-publicity within the sector generated by the preliminary inspections and focus groups, as well as the main phase of the intervention); "post-intervention reinforcement" (1993-96; see above); "late post-intervention" (1997-2000), and "very late post-intervention" (2001-03).

\section{Statistical analysis}

For each industrial sector, rates of eye injuries in each analytical period were estimated as the number of eye injuries divided by the number of workers at risk (based on the ISTAT industrial census data). Rates of non-eye injuries were estimated in a similar way. In order to assess the effectiveness of the intervention, we first compared the rates of eye injuries and non-eye injuries in each sector, calculating incidence rate ratios (IRR) and performing a non-parametric test for trend across ordered groups (that is, study periods). To identify determinants of eye injury rates, we performed a Poisson regression in which we modelled the eye injury rates for each sector, period and interaction, adjusting for non-eye injury rates by representing log rates as a linear function of the predictor variables of interest. ${ }^{11}{ }^{12}$ This adjusted model can be written as:

$\log ($ eye injury rate $)=\beta_{0}+\beta_{1}$ (sector $)+\beta_{2}$ (period $)+$ $\beta_{3}($ sector $\times$ period $)+\beta_{4}($ non-eye injury rate $)$.

We then examined the trend (adjusted for non-eye injury rates) of all levels of the three factors (that is, sector, period, and interaction). IRR and 95\% confidence intervals (95\% CI) were calculated as measures of association. A likelihood ratio test was performed to compare the results of the full model with those of a model without interaction terms. Percentage declines in eye injuries with respect to reference categories were calculated as $100 \times\left(1-\mathrm{e}^{\text {(trend parameter estimate) }}\right)$, where the trend parameter estimate is the fitted value of the $\beta$ regression coefficient. Stata 8.0 SE software (Stata

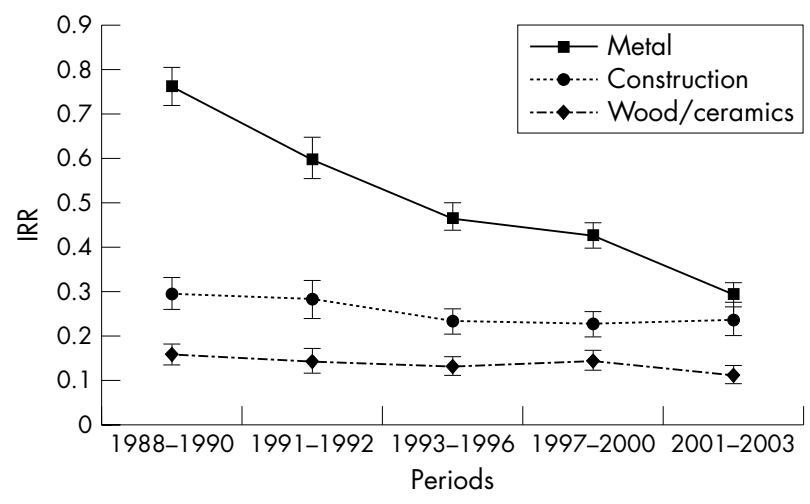

Figure 2 Incidence rate ratios in the metal and comparison (construction, wood/ceramics) sectors in the various study periods (preintervention, 1988-90; peri-intervention, 1991-92; post-intervention reinforcement, 1993-96; late post-intervention, 1997-2000; very late post-intervention, 2001-03).
Corporation, Texas) was used for all analyses, with significance set at $\mathrm{p}<0.05$.

\section{RESULTS}

Figure 1 shows the indexed trends for eye and non-eye injury rates in each of the three different industrial sectors over the five periods under analysis. In line with a general national trend, ${ }^{13}$ overall reductions were observable for both eye and non-eye injuries in each of the sectors. However, the sharpest reduction was for eye injury rate among metal workers, which fell by about $80 \%$ during the overall study period. Eye and non-eye injury rates are reported with their respective IRR in table 1 and fig 2.

Trend analysis revealed significantly greater reductions in eye injury rates with respect to non-eye injury rates in the metal sector $(p=0.05)$, but not in the construction or wood/ ceramics sectors during the overall study period.

Based on the likelihood ratio test, the Poisson regression model containing the interaction terms between periods and sectors was chosen $(\mathrm{LR}=38.25, \mathrm{p}<0.001)$. Table 2 reports the results of this model.

With respect to workers in the wood/ceramics sector (taken as reference category), metal workers had an almost fivefold risk of an eye injury (IRR $=4.93,95 \%$ CI 4.25 to 5.73 ), while construction workers had a slightly greater than twofold risk (IRR $=2.24,95 \%$ CI 1.46 to 3.43$)$. Although the periods did not by themselves determine an overall reduction in eye injuries, the interaction terms between period and sector turned out to be significant for the metal sector when crossed with the "post-intervention reinforcement" (IRR $=0.77,95 \%$ CI 0.61 to 0.97 ; \% decline $=23.4$ ), the "late post-intervention" (IRR $=0.63,95 \%$ CI 0.50 to 0.79 ; \% decline $=37.4)$, and the "very late post-intervention" (IRR $=0.58,95 \%$ CI 0.43 to $0.77 ; \%$ decline $=42.4$ ) periods, suggesting a sustained reduction in eye injury risk following the main intervention. The only other significant interaction was recorded in the construction sector crossed with the fourth ("late postintervention") period (IRR $=0.67,95 \%$ CI 0.50 to 0.90 ; $\%$ decline $=32.8$ ).

\section{DISCUSSION}

Relatively few planned interventions aimed at reducing the incidence of work related eye injuries have been described, ${ }^{6}$ the most recent dating from over 10 years ago. ${ }^{14}$ None of these reports (which tended to consider specific groups of workers or single factories most often using an observational or pre-post intervention study design) focused on evidence of effect in terms of ultimate reduction in the burden of injuries. ${ }^{6}$ To our knowledge, the present study provides the first assessment of the long term effectiveness of such a campaign. Our data provide suggestive evidence that a tailored, multicomponent campaign can bring about a lasting reduction in eye injuries.

The multicomponent intervention under assessment was extensive and carefully coordinated (with tripartite collaboration from Employers' Associations, Trade Unions, and Public Occupational Health Services, the latter providing the deterrent of official labour inspections for "post-intervention reinforcement"). We assessed the effectiveness of the intervention (corresponding to the last step in the Centers for Disease Control and Prevention model ${ }^{15}$ ) in terms of decreases in rates of work related eye injuries requiring firstaid treatment. Our analysis was primarily based on the comprehensive data provided by the established local surveillance system for occupational injuries, including cases with less than four days off work that in Italy are not recorded elsewhere (an important consideration, since many occupational eye injuries are not severe enough to require time away from work). ${ }^{16}$ This system was set up by the single 
Table 1 Eye and non-eye injury rates (per 1000 person-years) in metal and comparison sectors during the different periods under analysis

\begin{tabular}{|c|c|c|c|c|c|}
\hline & $\begin{array}{l}1988-90 \\
\text { (pre-intervention) }\end{array}$ & $\begin{array}{l}\text { 1991-92 } \\
\text { (peri-intervention) }\end{array}$ & $\begin{array}{l}1993-96 \\
\text { (post-intervention } \\
\text { reinforcement) }\end{array}$ & $\begin{array}{l}\text { 1997-2000 } \\
\text { (late post-intervention) }\end{array}$ & $\begin{array}{l}2001-03 \\
\text { (very late post- } \\
\text { intervention) }\end{array}$ \\
\hline \multicolumn{6}{|l|}{ Metal } \\
\hline Eye injury rates (n/N) & $167.52(2149 / 12828)$ & $113.19(968 / 8552)$ & $69.82(1310 / 18763)$ & $54.23(1097 / 20230)$ & $35.31(560 / 15858)$ \\
\hline Non-eye injury rates $(\mathrm{n} / \mathrm{N})$ & $220.30(2826 / 12828)$ & $189.43(1620 / 8552)$ & $150.30(2820 / 18763)$ & $128.13(2592 / 20230)$ & $122.34(1940 / 15858)$ \\
\hline $\operatorname{IRR}^{*}(95 \% \mathrm{CI})$ & $0.76(0.72$ to 0.80$)$ & $0.60(0.55$ to 0.65$)$ & $0.46(0.43$ to 0.50$)$ & $0.42(0.39$ to 0.45$)$ & $0.29(0.26$ to 0.32$)$ \\
\hline \multicolumn{6}{|l|}{${ }^{*} p=0.05$ at test for trend } \\
\hline \multicolumn{6}{|l|}{ Construction } \\
\hline Eye injury rates $(n / N)$ & $32.21(341 / 10587)$ & $32.30(228 / 7058)$ & 21.57 (322/14929) & $18.87(274 / 14522)$ & $18.59(193 / 10383)$ \\
\hline Non-eye injury rates $(n / N)$ & 109.85 (1163/10587) & $115.90(818 / 7058)$ & 93.91 (1402/14929) & $85.11(1236 / 14522)$ & $79.94(830 / 10383)$ \\
\hline $\begin{array}{l}\text { IRR }+(95 \% \mathrm{CI}) \\
t p=0.16 \text { at test for trend }\end{array}$ & $0.29(0.26$ to 0.33$)$ & $0.28(0.24$ to 0.32$)$ & $0.23(0.20$ to 0.26$)$ & $0.22(0.19$ to 0.25$)$ & $0.23(0.20$ to 0.27$)$ \\
\hline \multicolumn{6}{|l|}{ Wood/ceramics } \\
\hline Eye injury rates $(n / N)$ & $34.67(190 / 5481)$ & $27.64(101 / 3654)$ & 22.05 (160/7257) & $21.71(175 / 8062)$ & $18.01(120 / 6663)$ \\
\hline Non-eye injury rates $(\mathrm{n} / \mathrm{N})$ & $222.59(1220 / 5481)$ & $200.05(731 / 3654)$ & $172.94(1255 / 7257)$ & $154.68(1247 / 8062)$ & $169.89(1132 / 6663)$ \\
\hline $\begin{array}{l}\text { IRR } \ddagger(95 \% \mathrm{Cl}) \\
\pm p=0.16 \text { at test for trend }\end{array}$ & $0.16(0.13$ to 0.18$)$ & $0.14(0.11$ to 0.17$)$ & $0.13(0.11$ to 0.15$)$ & $0.14(0.12$ to 0.16$)$ & $0.11(0.09$ to 0.13$)$ \\
\hline
\end{tabular}

hospital in the study zone, which for logistic reasons provides a universal point of reference for the local population: the emergency department of the hospital is the only first-aid centre in the area for injuries of any kind, including ophthalmologic ones. For first-aid treatment, injured workers are practically obliged to visit the hospital since the very small factories (commonly employing no more than about 20 workers) that characterise the zone do not normally provide internal medical assistance, and in Italy hospital emergency departments provide the single source of public first-aid assistance (accounting for more than 90\% of the first certificates of work related accidents in the study area).

The study design was determined by practical considerations. In any case, since the intervention was implemented by the local occupational health authority as a much needed community health measure in response to the particularly high number of eye injuries recorded among local metal workers (a "reactive" rather than "proactive" intervention), a randomised study would not have been ethically appropriate.
Instead, to look for evidence of effectiveness we performed a comparison with other industrial sectors (construction and wood/ceramics) that are widely represented in the study zone, considering the incidence of eye injuries with respect to all other occupational injuries over five periods ("preintervention", "peri-intervention" (that is, a two year period selected to take in likely effects of the pre-publicity within the sector generated by the preliminary inspections and focus groups, as well as the main phase of the intervention), "postintervention reinforcement", "late post-intervention", and "very late post-intervention"). Availability of a reliable centralised workforce database (national industrial census data) enabled us to be confident regarding the denominators used for controlled assessment of trends in the rates of eye injuries.

Our Poisson model (including interaction terms between each of the three sectors and the five periods under analysis, adjusted for rates of non-eye injuries) revealed evidence of effectiveness both in the short term ("post-intervention

Table 2 Poisson regression model of eye injury rates (adjusted for non-eye injury rates) for each sector, period, and interaction

\begin{tabular}{|c|c|c|c|c|}
\hline & IRR & $95 \% \mathrm{Cl}$ & $\mathrm{p}$ value & $\%$ decline $^{*}$ \\
\hline \multicolumn{5}{|l|}{ Sectors } \\
\hline Wood/ceramics $\dagger$ & 1.00 & - & - & \\
\hline Metal & 4.93 & 4.25 to 5.73 & $<0.001$ & \\
\hline Construction & 2.24 & 1.46 to 3.43 & $<0.001$ & \\
\hline \multicolumn{5}{|l|}{ Periods } \\
\hline Pre-intervention (1988-90)† & 1.00 & - & - & - \\
\hline Peri-intervention (1991-92) & 0.95 & 0.74 to 1.23 & 0.717 & 4.6 \\
\hline Post-intervention reinforcement (1993-96) & 0.94 & 0.72 to 1.23 & 0.650 & 6.1 \\
\hline Late post-intervention (1997-2000) & 1.06 & 0.78 to 1.45 & 0.704 & -6.2 \\
\hline Very late post-intervention (2001-03) & 0.79 & 0.59 to 1.05 & 0.107 & 21.4 \\
\hline \multicolumn{5}{|l|}{ Interactionsł } \\
\hline Metal-Peri-intervention (1991-92) & 0.90 & 0.70 to 1.16 & 0.423 & 9.9 \\
\hline Metal-Post-intervention reinforcement (1993-96) & 0.77 & 0.61 to 0.97 & 0.024 & 23.4 \\
\hline Metal-Late post-intervention (1997-2000) & 0.63 & 0.50 to 0.79 & $<0.001$ & 37.4 \\
\hline Metal-Very late post-intervention (2001-03) & 0.58 & 0.43 to 0.77 & $<0.001$ & 42.4 \\
\hline Construction-Peri-intervention (1991-92) & 1.01 & 0.74 to 1.37 & 0.960 & -0.8 \\
\hline Construction-Post-intervention reinforcement (1993-96) & 0.81 & 0.61 to 1.08 & 0.144 & 19.1 \\
\hline Construction-Late post-intervention (1997-2000) & 0.67 & 0.50 to 0.90 & 0.009 & 32.8 \\
\hline Construction-Very late post-intervention (2001-03) & 0.93 & 0.69 to 1.26 & 0.645 & 6.8 \\
\hline
\end{tabular}




\section{Main messages}

- This analysis suggests that a carefully coordinated, extensive, multicomponent intervention may lead to lasting reductions in the burden of eye injuries.

- Conclusive demonstration of effectiveness requires evidence from randomised studies.

reinforcement" period) and in the long term ("late" and "very late" post-intervention period). These findings suggest that a specifically tailored educational campaign may effectively determine a long term reduction in eye injuries in a high risk sector.

In the context of a generalised reduction in work related injuries in all the three considered sectors (in line with trends observed in different industrial sectors in all Italy ${ }^{13}$ ), the only factor specifically related to a significant reduction in the burden of eye injuries was employment in the metal worker subset during the "post-intervention reinforcement" period, and in the "late" and "very late" post-intervention periods. The significantly reduced IRR for the construction sector in the "late post-intervention" period was an isolated finding, which could be attributed to the many unannounced inspections in construction sites during these years.

In view of the non-randomised nature of the study, several important potential sources of bias must be considered. The reliability of our workforce data should obviate bias due to employment fluctuations in the three sectors during the study period. Bias might have stemmed from introduction of new, safer technology in the metal-ware factories (of note, production levels in the metal sector appear to have been maintained over the study period (data not shown), which was not characterised by economic recessions/booms). In particular, introduction of cybernetic welding procedures in the early 1990s could have led to a reduction in the relatively small subset of eye injuries related to ultraviolet exposure. However, in this case we should have been able to find a similar trend also in loco-regional data: examining INAIL data referring to four other nearby, surrounding provinces (Florence, Modena, Ferrara, and Forlì-Cesena) not exposed to the Imola intervention, we were unable to find evidence of any specific time trend for the metal sector (data not shown). Although the sectors under study were evenly distributed as regards proximity to the hospital (data not shown), some imbalance is possible as regards age and gender (available data suggest a higher proportion of women workers in the ceramics sector).

The present study cannot provide information on the relative influence of the various components of our intervention (including focus groups with management; preliminary/main/reinforcement inspections of factories; worker education by booklet, local television/radio broadcasts, and newspaper articles). The one existing systematic review on the effectiveness of interventions to prevent work related eye injuries provided evidence that "policy changes may be effective in changing behaviours and reducing eye injuries in manufacturing settings, either in conjunction with a broader program focused on eye safety, or by policy alone". ${ }^{6}$ Policy changes can provide an important way of overcoming the resistance posed by specific, ingrained work cultures. The four year "post-intervention reinforcement" period following the main intervention (characterised by the deterrent of unannounced official inspections bearing the threat of sanctions) may conceivably have provided a stimulus for employers to make lasting policy changes. Furthermore, the close collaboration of the Local Employers' Association (as

\section{Policy implications}

- This study provides suggestive evidence that a carefully planned multicomponent preventive intervention (including tripartite collaboration from Employers' Associations, Trade Unions, and Public Occupational Health Services with the deterrent of official postintervention labour inspections) may be able to determine long term reductions in occupational eye injuries.

well as Trade Unions) in the intervention may have provided a further source of encouragement for reconsideration of policy. We think that the possible role of carefully devised television interviews with experts also deserves reflection. Although little is known about its specific influence in preventive interventions, ${ }^{17}$ we suspect that in our setting the perceived "authority" of television appearances by qualified experts may have provided a valuable source of psychological reinforcement to encourage employees to modify traditionally acquired working habits. These issues might deserve consideration in further studies.

In conclusion, the present work provides some evidence of the possible effectiveness of an eye injury prevention campaign in the manufacturing industry. Our study suggests that a carefully coordinated, extensive, multicomponent intervention can lead to lasting reductions in the burden of eye injuries. Conclusive demonstration of this concept requires evidence from randomised studies.

\section{ACKNOWLEDGEMENTS}

We would like to thank Roberto Baroncini, Alessandra Giovanardi, and Paola Folletti of the Occupational Health Service of Imola Local Health Authority, who performed the preliminary (and other) inspections of the metal-ware factories. We are grateful to Robin MT Cooke for writing assistance and scientific editing.

\section{Authors' affiliations}

G Mancini, Occupational Health Service, Azienda USL di Ravenna, Ravenna, Italy (formerly at Occupational Health Service, Azienda USL di Imola, Imola)

A Baldasseroni, Epidemiology Unit, Azienda USL di Firenze, Florence, Italy

G Laffi, Occupational Health Service, Azienda USL di Imola, Imola, Italy S Curti, Laboratory of Epidemiology, Occupational Medicine Unit, Policlinico S. Orsola-Malpighi, Bologna, Italy

S Mattioli, Alma Mater Studiorum-University of Bologna, Laboratory of Epidemiology, Occupational Medicine Unit, Policlinico S. Orsola-

Malpighi, Bologna, Italy

F S Violante, Alma Mater Studiorum-University of Bologna,

Occupational Medicine Unit, Policlinico S. Orsola-Malpighi, Bologna, Italy

Competing interests: none declared

\section{REFERENCES}

1 Baker RS, Wilson RM, Flowers CW Jr, et al. A population-based survey of hospitalized work-related ocular injury: diagnoses, cause of injury, resource utilization, and hospitalization outcome. Ophthalmic Epidemiol 1999;6:159-69.

2 McCarty CA, Fu CL, Taylor HR. Epidemiology of ocular trauma in Australia. Ophthalmology 1999;106:1847-52.

3 Islam SS, Doyle EJ, Velilla A, et al. Epidemiology of compensable work-related ocular injuries and illnesses: incidence and risk factors. J Occup Environ Med 2000;42:575-81.

4 Bureau of Labour Statistics (BLS). Number of non-fatal occupational injuries and illnesses involving days away from work by selected injury or illness characteristics and industry, 2000. News release, Table 4. Available at: ftp:// ftp.bls.gov/pub/news.release/History/osh2.04102002.news (accessed 20 December 2004). 
5 Italian National Institute of Insurance for Occupational Accidents (INAIL) Number of eye-injuries involving more than three days away from work, 1999. Available at: http://bancadati.inail.it/prevenzionale/Indennizzati.htm (accessed 20 December 2004).

6 Lipscomb HJ. Effectiveness of interventions to prevent work-related eye injuries. Am J Prev Med 2000;18:27-32.

7 Smith MJ, Anger WK, Uslan SS. Behavioral modification applied to occupational safety. J Safety Res 1978;10:87-8.

8 Schein OD, Hibberd PL, Shingleton BJ, et al. The spectrum and burden of ocular injury. Ophthalmology 1988;95:300-5.

9 Leino T, Räsänen K, Liira J, et al. Comparative analysis of occupational health system and practices as part of preventive health care systems in seven European countries - document based analysis. European Commission INCOCopernicus program report of the project no PL 973108. Helsinki: Finnish Institute of Occupational Health, 1999

10 ISTAT, Censimento Industria e Servizi (1991, 1996, 2001). Available at: http://www. istat.it/Censimenti/index.htm (accessed 20 December 2004)
11 Frome EL, Checkoway $\mathrm{H}$. Use of Poisson regression models in estimating incidence rates and ratios. Am J Epidemiol 1985; 121:309-23.

12 Bailer AJ, Stayner LT, Stout NA, et al. Trends in rates of occupational fatal injuries in the United States (1983-92). Occup Environ Med 1998:55:485-9.

13 Fabiano B, Curro F, Pastorino R. Occupational injuries in ltaly: risk factors and long term trend (1951-98). Occup Environ Med 2001;58:330-8.

14 Streff FM, Kalsher MJ, Geller ES. Developing efficient workplace safety programs: observations of response covariation. J Org Behav Manag 1993:13:3-14.

15 Teutsch SM. A framework for assessing the effectiveness of disease and injury prevention. MMWR Recomm Rep 1992;41:1-12.

16 Lipscomb HJ, Dement JM, McDougall V, et al. Work-related eye injuries among union carpenters. Appl Occup Environ Hyg 1999; 14:665-76.

17 Grilli R, Ramsay C, Minozzi S. Mass media interventions: effects on health services utilisation (Cochrane review). The Cochrane Library, Issue 4, 2004 Available at http://www.cochrane.org/cochrane/revabstr/AB000389.htm (accessed 20 December 2004).

Answers to questions on Health impact assessment by M Joffe and J Mindell, on pages $907-912$

(1) (a) $\mathrm{T}$; (b) $\mathrm{F}$; (c) F; (d) $\mathrm{T}$; (e) F

(2) (a) F; (b) $T_{\text {; }}$ (c) F; (d) F; (e) F

(3) (a) F; (b) T; (c) F; (d) T; (e) F

(4) (a) F; (b) T; (c) T; (d) T; (e) T

(5) (a) $\mathrm{T}$; (b) $\mathrm{T}$; (c) T; (d) $\mathrm{T}$; (e) F

(6) (a) F; (b) F; (c) F; (d) $\mathrm{T}$; (e) F 